\title{
Insulin Inhibits and Oral Sucrose Increases Neointimal Growth after Arterial Injury in Rats
}

\author{
Danna M. Breen ${ }^{a} \quad$ Jiwanjeet K. Dhaliwalla Kalam K. Chan ${ }^{a} \quad J u n e ~ G u o^{a}$ \\ Loretta Lam $^{a}$ Michelle P. Bendeck ${ }^{b, c, d}$ Adria Giacca ${ }^{a, b}, d$ \\ Departments of a Physiology, ${ }^{b}$ Medicine and ${ }^{\mathrm{C}}$ Laboratory Medicine and Pathobiology, and ${ }^{\mathrm{d}}$ Institute of \\ Medical Science, University of Toronto, Toronto, Ont., Canada
}

\section{Key Words}

Angioplasty $\cdot$ Glucose $\cdot$ Insulin $\cdot$ Neointima $\cdot$ Proliferation $\cdot$ Sucrose

\begin{abstract}
Background/Aims: In our previous studies, rats on insulin treatment ( $5 \mathrm{U} /$ day) and oral glucose to avoid hypoglycemia had reduced neointimal growth after arterial injury. However, plasma glucose in the insulin-treated rats was lower than normal and the effect of oral glucose remained undetermined. In this study, the effects of normoglycemic hyperinsulinemia and oral glucose or sucrose were investigated in the same model. Methods: Rats were divided into 6 groups: (1) control implants and tap water; (2) insulin implants (5 U/ day) and oral glucose + i.p. glucose to avoid any glucose lowering; (3) insulin implants (4 U/day) and oral glucose; (4) insulin implants (4 U/day) and oral sucrose; (5) control implants and oral glucose, and (6) control implants and oral sucrose. Results: Insulin treatment at both doses reduced neointimal area $(\mathrm{p}<0.001) 14$ days after injury in rats receiving oral glucose but not in those receiving oral sucrose. Oral glucose, without insulin, had no effect on neointimal formation, whereas oral sucrose increased neointimal growth $(p<0.05)$. Oral sucrose $(p<0.05)$ but not oral glucose decreased insulin
\end{abstract}

sensitivity measured with hyperinsulinemic clamps. Conclusions: (1) Insulin decreases neointimal growth after arterial injury independent of glucose-lowering or oral glucose administration and (2) oral sucrose per se affects neointimal growth.

Copyright $\odot 2010$ S. Karger AG, Basel

\section{Introduction}

Metabolic syndrome is a common disorder characterized by the development of a cluster of abnormalities which include insulin resistance, compensatory hyperinsulinemia, glucose intolerance (type 2 diabetes, impaired glucose tolerance, or impaired fasting glucose), central obesity, dyslipidemia, hypertension and microalbuminuria [1-3]. The metabolic syndrome affects up to $25 \%$ of the population [1] and is associated with an increased risk of atherosclerosis and restenosis [4-6] in part because of insulin resistance/hyperinsulinemia per se $[7,8]$.

In the metabolic syndrome, hyperinsulinemia and insulin resistance coexist, therefore it is unclear which is the main risk factor for atherosclerosis and restenosis. In our previous study, we investigated the effect of hyperinsulinemia on neointimal hyperplasia after balloon catheter

\section{KARGER}

Fax +41613061234 E-Mail karger@karger.ch www.karger.com
(C) 2010 S. Karger AG, Basel

$1018-1172 / 10 / 0475-0412 \$ 26.00 / 0$

Accessible online at:

www.karger.com/jvr
Dr. Adria Giacca

Department of Physiology, University of Toronto

Medical Sciences Building, 1 King's College Circle, Room 3336

Toronto, ON M5S 1A8 (Canada)

Tel. +1 416978 0167, Fax +1 416978 4373, E-Mail adria.giacca@utoronto.ca 
injury, a model of restenosis. Normal rats on insulin treatment (5 U/day) and given a control diet had significantly reduced neointimal growth at 14 days after arterial injury [9]. However, the beneficial effect of insulin was diminished after a high-fat diet, which induces insulin resistance similar to the metabolic syndrome. The decrease in neointimal area induced after insulin treatment in rats fed the control diet occurred despite an increase in smooth muscle cell (SMC) proliferation [9]. However, one limitation of the study was that the plasma glucose levels in the insulin-treated rats were lower than normal, and it has been shown in previous studies that hypoglycemia induced by insulin can decrease DNA synthesis in the rat aorta up to 4 days after arterial injury [10]. Although in our study the plasma glucose levels were not in the hypoglycemic range, the effect of hyperinsulinemia was not studied in the presence of normal plasma glucose.

In another study, we investigated the effects of normoglycemic hyperinsulinemia on neointimal growth after balloon catheter injury of the carotid artery in rats; however, a lower dose of insulin was used. We have shown that insulin treatment ( $3 \mathrm{U} /$ day) in normal rats given oral glucose and standard chow did not significantly decrease neointimal area at 14 days after arterial injury but decreased neointimal area at 28 days after arterial injury [11]. Taken together, the results of the 2 studies suggest that the action of insulin on neointimal growth may be dose-dependent; however, it is also possible that in the first study neointimal growth decreased significantly because of glucose lowering rather than the higher insulin dose.

A common limitation of the 2 studies is that the insulin-treated rats were given oral glucose to help maintain plasma glucose levels within the normal range and the effect of oral glucose was not assessed. It is theoretically possible that the decrease in neointimal growth is caused by the oral glucose rather than insulin. Glucose intake orally stimulates gastrointestinal hormones, such as glucagon-like peptide-1 and gastric inhibitory peptide, whose receptors are present in vascular cells. Glucagonlike peptide-1 has been reported to induce vasodilation $[12,13]$ and improve endothelial function [14], whereas in dogs gastric inhibitory peptide was found to affect splanchnic hemodynamics [15]. Thus these hormones can have vascular actions, although their effect on neointimal growth has not been investigated.

The purpose of this study was to investigate the effects of insulin treatment at the higher dose of $5 \mathrm{U} /$ day on neointimal growth after arterial injury, while maintaining the blood glucose levels within the normal range. We have also determined the effect of oral glucose, without insulin treatment, on neointimal growth after arterial injury. In addition, we wished to investigate the effect of oral sucrose alone and in combination with insulin, as a recently published study found that neointimal growth was actually increased in insulin-treated rats after balloon catheter injury while normoglycemia was maintained with $10 \%$ oral sucrose [16], instead of the $40 \%$ glucose in water used in our studies where insulin had a protective effect. Sucrose contains fructose, which is a known inducer of insulin resistance [17], thus we speculate that sucrose alone (the effect of which was not evaluated in the previous study) may increase neointimal growth.

\section{Materials and Methods}

\section{Animal Models}

Male Sprague-Dawley rats (Charles River, Constant, Que., Canada), weighing between 350 and $400 \mathrm{~g}$, were used. The rats were divided into 6 groups: (1) rats with blank implants and access to tap water (control $=\mathrm{C})$; (2) rats with insulin implant $(5 \mathrm{U} /$ day) and access to glucose in their drinking water as a $40 \%(\mathrm{w} / \mathrm{v})$ solution [insulin (5 U/day) $+40 \%$ oral glucose $=\mathrm{I} 5 \mathrm{G}$ ] as in Kim et al. [9] but with i.p. glucose infusion (25\%) to avoid any glucose lowering; (3) rats with insulin implant ( 4 U/day, which is similar to $\sim 3.9$ U/day used in Foster et al. [16]) and access to glucose in their drinking water as a $40 \%(\mathrm{w} / \mathrm{v})$ solution [insulin (4 U/day) $+40 \%$ oral glucose $=\mathrm{I} 4 \mathrm{G}]$; (4) rats with insulin implant (4 U/day) and access to sucrose in their drinking water as a $10 \%(\mathrm{w} / \mathrm{v})$ solution as in Foster et al. [16] [insulin (4 U/day) + 10\% oral sucrose = I4S]; (5) rats with blank implants and access to glucose in their drinking water as a $40 \%(\mathrm{w} / \mathrm{v})$ solution (control glucose $=\mathrm{CG})$, and (6) rats with blank implants and access to sucrose in their drinking water as $10 \%(\mathrm{w} / \mathrm{v})$ solution $($ control sucrose $=\mathrm{CS})$. The rats were fed a normal-fat diet, consisting of $12 \%$ fat in calories as used in Kim et al. [9]. This diet, despite having the same fat content of the standard chow used in another study where we found insulin to decrease neointimal growth [11], was defined as low-fat in Kim et al. [9] to contrast it to the high-fat diet also used in that paper. The rats were implanted with either insulin-releasing implants ( 5 or 4 U/day; LinShin Canada Inc.) or blank implants using isoflurane gas, also as in Kim et al. [9], 2 days before balloon angioplasty. Previous reports have demonstrated sustained release and action of the insulin implants ( $>40$ days) after implantation [18]. The rats were housed in the University of Toronto's Department of Comparative Medicine and exposed to a 12-hour:12-hour lightdark cycle. The animal care committee of the University of Toronto approved all procedures.

\section{Surgical Procedure}

Two days after blank/insulin capsule implantation, arterial injury was performed by balloon angioplasty only on rats with blood glucose levels greater than $4.0 \mathrm{mM}$. Rats were anesthetized with a ketamine:xylazine:acepromazine cocktail (87:1.7:0.4 mg/ $\mathrm{ml}, 1 \mu \mathrm{l} / \mathrm{g}$ body weight) and the left common carotid artery was injured by a 2 F (Fogarty, No. 2; Baxter, Toronto, Ont., Canada) 
balloon embolectomy catheter which was inflated and withdrawn 4 times to denude the vessel of endothelium. After balloon injury, an intraperitoneal catheter (PE-50; Cay Adams, Boston, Mass., USA) was inserted for infusion of $25 \%$ glucose to maintain normal blood glucose levels (control rats received continuous infusion of saline) after surgery (when rats do not eat or drink) and the rate of infusion was adjusted according to frequent glycemic determination (every $2 \mathrm{~h}$ ). After recovery from surgery the insulin (5 U/day)-treated rats still received continuous glucose infusion for 14 days to ensure the blood glucose levels remained in the normal range and the infusion rate was monitored on a daily basis, whereas the control rats received saline infusion. In control rats we compared those receiving saline infusion via the i.p. catheter to rats without the i.p. catheter and found no difference in neointimal area ( $p>0.05$; table 1$)$. Therefore, data for these animals was pooled as a single control group $(C)$. In the rats receiving insulin at $4 \mathrm{U} /$ day, an i.p. catheter for glucose infusion was not used. Oral glucose or sucrose was used alone to maintain normoglycemia to be consistent with Foster et al. [16]. Blood glucose levels were measured daily either in the fasted or fed state, using a glucometer (Glucometer Elite; Bayer Inc.). Both fasting and fed blood glucose samples were measured at the same time of day $(\sim 10$ a.m.). Random fed glucose levels were also measured to ensure that normoglycemia was maintained throughout the fed state. To obtain fasting blood glucose levels, rats were fasted once for $\sim 16$ h (tap water $/ 40 \%$ glucose solution $/ 10 \%$ sucrose solution was given without food).

\section{Vessel and Blood Sample Collection}

Two weeks after arterial injury, the rats were sacrificed. To label proliferating SMCs, rats were injected i.p. with 3 doses of 25 $\mathrm{mg} / \mathrm{kg}$ 5-bromo-2'-deoxyuridine (BrdU; Sigma) at 17, 9 and $1 \mathrm{~h}$ before sacrifice. Approximately half the rats were sacrificed in the fed state and half in the fasted state in order to obtain blood samples in different metabolic states. Under general anesthesia, blood samples were collected via cardiac puncture for insulin, triglyceride and free fatty acid measurements. Following blood sample collections, rats were sacrificed via anesthetic overdose and subjected to retrograde perfusion through the abdominal aorta with Krebs-Ringer solution and then with $4 \%$ buffered paraformaldehyde at the physiologic pressure $(110 \mathrm{~mm} \mathrm{Hg})$. A 2-cm length of vessel was excised from the middle of each of the left and right common carotid arteries and immersed in $4 \%$ buffered paraformaldehyde for $>48 \mathrm{~h}$. All the vessel samples were embedded in paraffin. The vessel samples were removed from the middle of the section to ensure that the vessel cross-sections used for analysis were sections of the common carotid artery with the most even vessel damage and within the arterial region of the vessel which never completely re-endothelializes. The vessels were used for morphometric analysis.

\section{Histomorphometry/Matrix Staining}

Neointimal and medial cross-sectional areas were measured on hematoxylin- and eosin-stained slides and analyzed using a computer-assisted morphometric system (Simple PCI, Compix Inc). Vessel images were obtained using a Nikon E600 microscope (Nikon) and digitized using a camera (model C4742-95-12NRB; Hamamatsu Inc.). Two separate cross-sections were measured on each carotid artery and averaged. This average value was used to represent each individual rat. Neointimal area was measured as
Table 1. Cross-sectional areas of the intima of carotid arteries from control rats measured at 14 days after vessel injury

i.p. catheter $(n=5) \quad$ Without i.p. catheter $(n=5)$

Intimal area, $\mathrm{mm}^{2} \quad 0.23 \pm 0.02 \quad 0.22 \pm 0.04$

Values are means \pm SEM.

No significant differences were found.

the area encompassed by the internal elastic lamina minus the observed lumen area (in this case the observed lumen area was determined by tracing around the inside edge of the vessel and calculating the area inside). Medial area was measured as the area encompassed by the external elastic lamina minus the area encompassed by the internal elastic lamina. Calculated lumen area was obtained by subtracting the neointimal area and the medial area from the total area encompassed by the external elastic lamina (total area was calculated using the external elastic lamina perimeter assuming circular geometry of the vessel). This method of obtaining lumen area avoids artifacts due to paraffin embedding.

Neointimal SMC proliferation was measured 14 days after carotid balloon injury with an anti-BrdU antibody (1:40 dilution; DAKO Corp.), as previously described [9]. Rats were injected i.p. with 3 doses of $25 \mathrm{mg} / \mathrm{kg}$ 5-bromo-2'-deoxyuridine (BrdU, a thymidine analog; Sigma) at 17, 9, and 1 hour before sacrifice to ensure that all SMC undergoing DNA synthesis within the 24-hour period prior to sacrifice were labeled.

\section{Vessel Cannulation}

Three days before the hyperinsulinemic-euglycemic clamp, indwelling catheters were inserted into the right internal jugular vein and the left common carotid artery. Polyethylene catheters (PE-50; Cay Adams, Boston, Mass., USA), each extended with a segment of silastic tubing (length of $3 \mathrm{~cm}$, internal diameter of 0.02 inches; Dow Corning, Midland, Mich., USA), were used for vascular catheterization. The venous catheter was extended to the level of the right atrium, and the arterial catheter was advanced to the level of the aortic arch. Both catheters were tunneled subcutaneously, fed through a subcutaneous interscapular implant, and exteriorized. Catheters were filled with a mixture of saline and heparin $(1,000 \mathrm{U} / \mathrm{ml})$ to maintain patency and were closed at the end with a metal pin.

\section{Hyperinsulinemic-Euglycemic Clamp}

After an overnight fast, insulin (Humulin R, $5 \mathrm{mU} / \mathrm{kg} / \mathrm{min}$ ) and glucose (variable rate) were infused through the jugular vein for $2 \mathrm{~h}$ to maintain euglycemia while blood samples were taken from the left carotid artery for plasma glucose measurements.

\section{Laboratory Methods}

Plasma insulin levels were determined by radioimmunoassay (RIA) using a kit from Linco Research Inc., St. Charles, Mo., USA. Plasma free fatty acid (FFA) levels were analyzed using an in vitro enzymatic colorimetric method (Wako Chemicals, Neuss, Germany). Plasma triglyceride levels were measured using a colorimetric kit from Roche Diagnostics (Laval, Que., Canada). 
Table 2. Daily fasting and fed plasma glucose levels over the treatment period

\begin{tabular}{|c|c|c|c|c|c|c|}
\hline & $C(n=10)$ & $\mathrm{I} 5 \mathrm{G}(\mathrm{n}=9)$ & $\mathrm{I} 4 \mathrm{G}(\mathrm{n}=8)$ & $\mathrm{I} 4 \mathrm{~S}(\mathrm{n}=8)$ & $\mathrm{CG}(\mathrm{n}=10)$ & $\operatorname{CS}(n=10)$ \\
\hline Fasting plasma glucose, $\mathrm{mM}^{\mathrm{a}}$ & $4.9 \pm 0.1$ & $4.0 \pm 0.2$ & $4.5 \pm 0.5$ & $3.2 \pm 0.3^{* * *}$ & $5.1 \pm 0.2$ & $6.3 \pm 0.1^{* *}$ \\
\hline Fed plasma glucose, $\mathrm{mM}^{\mathrm{b}}$ & $6.1 \pm 0.1$ & $6.1 \pm 0.2$ & $6.1 \pm 0.2$ & $5.9 \pm 0.4$ & $6.1 \pm 0.1$ & $6.2 \pm 0.1$ \\
\hline
\end{tabular}

Glucose levels were measured daily for 14 days. $\mathrm{C}=$ Control; $\mathrm{I} 5 \mathrm{G}=$ insulin $(5 \mathrm{U} /$ day $)+$ oral glucose; $\mathrm{I} 4 \mathrm{G}=\mathrm{insulin}(4 \mathrm{U} / \mathrm{day})+$ oral glucose; $\mathrm{I} 4 \mathrm{~S}=$ insulin $\left(4 \mathrm{U} /\right.$ day) + oral sucrose; $\mathrm{CG}=$ oral glucose; $\mathrm{CS}=$ oral sucrose. ${ }^{\text {a }}$ Data are means \pm SEM of individual average glucose levels taken over the treatment period after an overnight 16 -hour fast. ${ }^{\mathrm{b}}$ Data are means \pm SEM of individual average glucose levels taken over the treatment period. ${ }^{* *} \mathrm{p}<0.01,{ }^{* * *} \mathrm{p}<0.001$ vs. C.

Table 3. Fasting plasma levels of insulin, triglycerides and FFA at 14 days after arterial injury

\begin{tabular}{|c|c|c|c|c|c|c|}
\hline & $C(n=5)$ & I5G $(n=4)$ & $\mathrm{I} 4 \mathrm{G}(\mathrm{n}=3)$ & $\mathrm{I} 4 \mathrm{~S}(\mathrm{n}=3)$ & $\mathrm{CG}(\mathrm{n}=5)$ & $\operatorname{CS}(n=4)$ \\
\hline Insulin, $\mathrm{pM}$ & $82 \pm 8$ & $1,442 \pm 223^{* * *}$ & $927 \pm 114^{* * *}$ & $704 \pm 83^{* * *}$ & $88 \pm 14$ & $109 \pm 7$ \\
\hline Triglycerides, mM & $0.72 \pm 0.16$ & $0.44 \pm 0.09$ & $0.65 \pm 0.07$ & $0.74 \pm 0.14$ & $0.67 \pm 0.12$ & $1.22 \pm 0.03$ \\
\hline $\mathrm{FFA}, \mu \mathrm{Eq} / \mathrm{l}$ & $632 \pm 118$ & $131 \pm 84^{*}$ & $105 \pm 38^{*}$ & $342 \pm 27$ & $329 \pm 75$ & $476 \pm 145$ \\
\hline
\end{tabular}

Treatment groups defined as in table 2. Data are expressed as means \pm SEM and represent values taken at sacrifice. ${ }^{*} \mathrm{p}<0.05$, ${ }^{* * *} \mathrm{p}<0.001$ vs. C.

Table 4. Fed plasma levels of insulin, triglycerides and FFA at 14 days after arterial injury

\begin{tabular}{|c|c|c|c|c|c|c|}
\hline & $C(n=5)$ & I5G $(n=5)$ & $\mathrm{I} 4 \mathrm{G}(\mathrm{n}=5)$ & $\mathrm{I} 4 \mathrm{~S}(\mathrm{n}=5)$ & $\mathrm{CG}(\mathrm{n}=5)$ & $\operatorname{CS}(n=6)$ \\
\hline Insulin, $\mathrm{pM}$ & $170 \pm 26$ & $1,420 \pm 373^{* * *}$ & $1,006 \pm 167^{*}$ & $969 \pm 100^{*}$ & $173 \pm 28$ & $171 \pm 20$ \\
\hline Triglycerides, mM & $1.23 \pm 0.19$ & $1.45 \pm 0.32$ & $1.30 \pm 0.26$ & $1.75 \pm 0.25$ & $1.55 \pm 0.32$ & $2.40 \pm 0.26$ \\
\hline $\mathrm{FFA}, \mu \mathrm{Eq} / \mathrm{l}$ & $230 \pm 14$ & $155 \pm 26$ & $210 \pm 23$ & $256 \pm 63$ & $275 \pm 75$ & $322 \pm 38$ \\
\hline
\end{tabular}

Treatment groups defined as in table 2. Data are expressed as means \pm SEM and represent values taken at sacrifice. ${ }^{*} \mathrm{p}<0.05$, ${ }^{* * *} \mathrm{p}<0.001$ vs. C.

\section{Statistical Analysis}

Values are expressed as mean \pm SEM of individual rat values. Statistical analysis was performed using analysis of variance (ANOVA) for repeated measurements (when appropriate) to test for significant differences among groups and the post hoc comparisons were performed with Tukey's t-test. Statistical calculations were performed using SAS software (Statistical Analysis System, Cary, N.C., USA). Significance was accepted at $\mathrm{p}<0.05$.

\section{Results}

\section{Metabolic Parameters}

Daily food intake, caloric intake, body weight change, as well as the fasting and fed plasma glucose levels was measured over the treatment period. Food intake was sig- nificantly less in all rats given oral glucose compared to the control group (C $24 \pm 1 \mathrm{~g}$ /day, I5G $9 \pm 2$ g/day, I4G $18 \pm 1 \mathrm{~g} /$ day, I4S $22 \pm 1 \mathrm{~g} /$ day, CG $14 \pm 2 \mathrm{~g} /$ day, CS 21 $\pm 1 \mathrm{~g} /$ day; $\mathrm{p}<0.01 \mathrm{I} 4 \mathrm{G}$ vs. C, $\mathrm{p}<0.001$ I5G and CG vs. C) because of the $40 \%$ glucose in water. Average daily caloric intake was not significantly different among groups (C $112 \pm 5 \mathrm{kcal} /$ day, I5G $111 \pm 9 \mathrm{kcal} /$ day, I4G $137 \pm 2$ $\mathrm{kcal} /$ day, I4S $133 \pm 8 \mathrm{kcal} /$ day, CG $101 \pm 9 \mathrm{kcal} /$ day, CS $120 \pm 5 \mathrm{kcal} /$ day). The change in body weight (data not shown) was also not significantly different among groups. Neither fasting nor fed plasma glucose (table 2) was different between control and insulin-treated rats receiving oral glucose; however, fasting plasma glucose was lower in insulin-treated rats receiving oral sucrose $(p<0.001)$ but greater in rats receiving oral sucrose alone $(\mathrm{p}<0.01)$. 


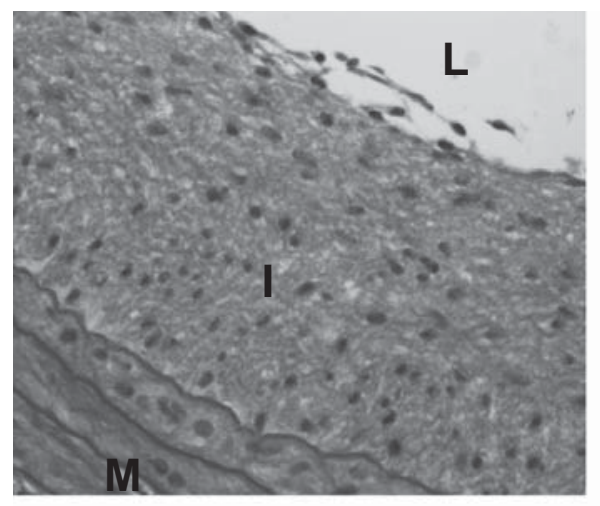

C

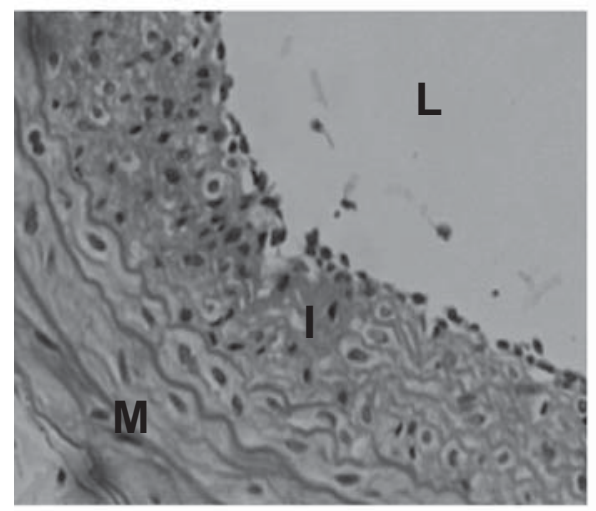

I4G

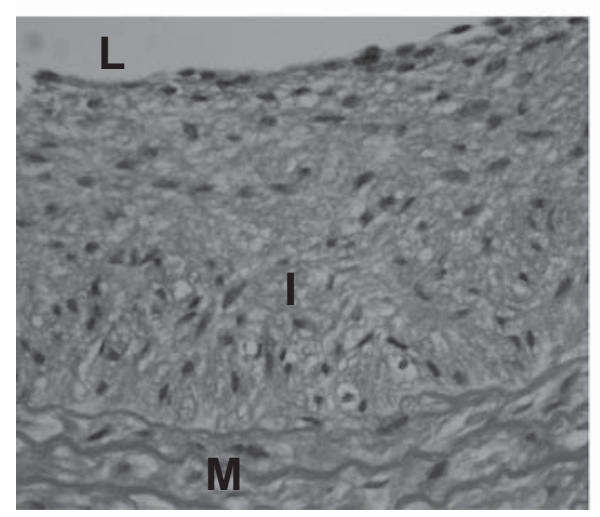

CG

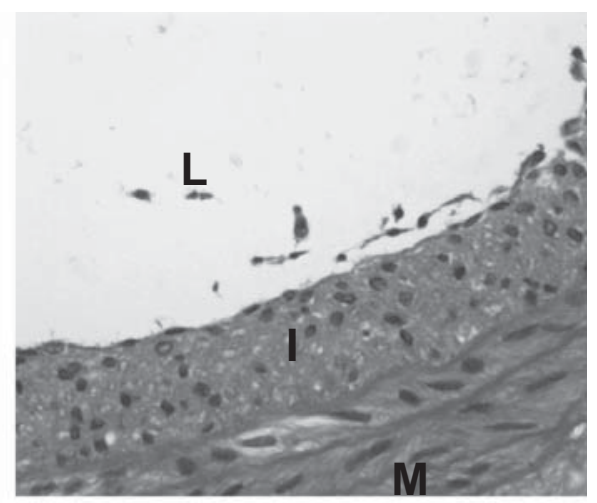

I5G

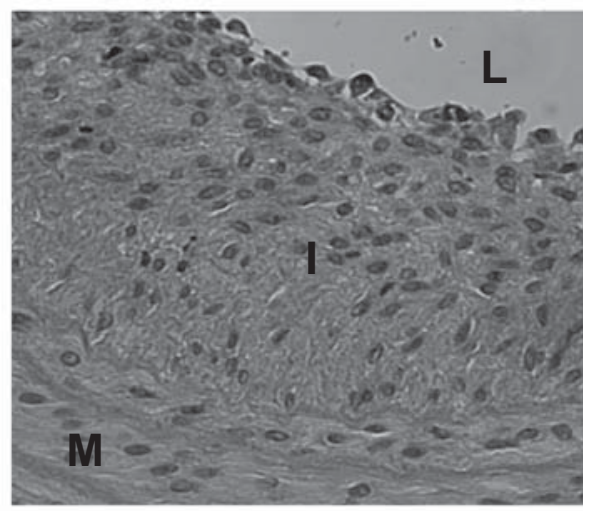

$14 S$

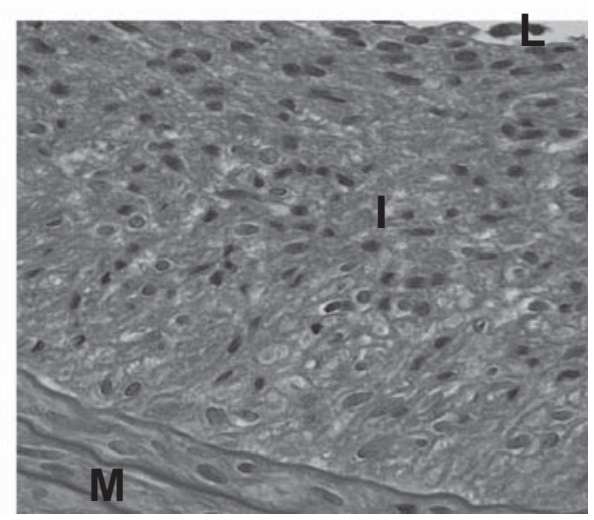

CS
Fig. 1. Representative photomicrographs of carotid artery cross-sections taken at 14 days after balloon injury $(\times 400) . \mathrm{L}=\mathrm{Lu}-$ men; $\mathrm{I}=$ intima; $\mathrm{M}=$ media. $\mathrm{C}=$ Control; $\mathrm{I} 5 \mathrm{G}=$ insulin $(5 \mathrm{U} /$ day $)+$ oral glucose; $\mathrm{I} 4 \mathrm{G}=$ insulin $(4 \mathrm{U} /$ day $)+$ oral glucose; $\mathrm{I} 4 \mathrm{~S}=$ insulin $(4 \mathrm{U} /$ day $)+$ oral sucrose; $\mathrm{CG}=$ oral glucose; $\mathrm{CS}=$ oral sucrose. er in the CS group ( $<<0.10$; table 3 ). The fasting FFA levels in the insulin-treated rats receiving oral glucose were significantly decreased ( $p<0.05)$, whereas in the insulin-treated rats receiving oral sucrose FFA only tended to decrease ( $p<0.10$; table 3$)$. In the fed state, the insulin levels were greater in the insulin-treated groups than in all other groups $(\mathrm{p}<0.05)$, as expected (table 4$)$. The CS group tended to have elevated fed triglyceride lev- 

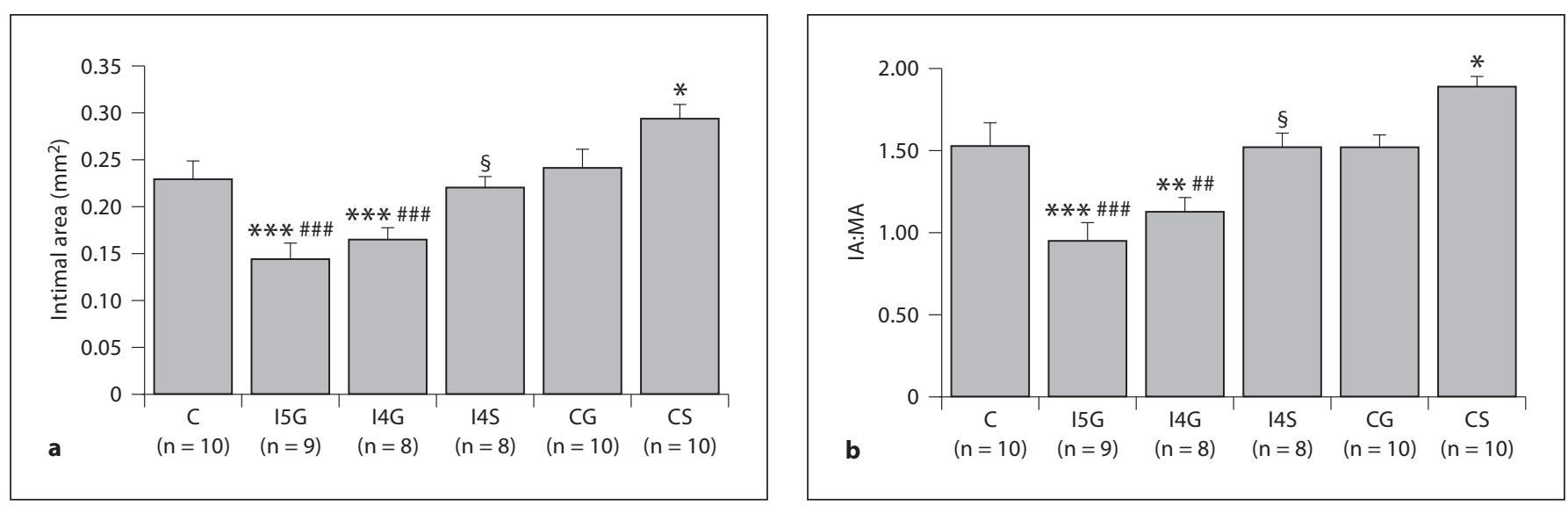

Fig. 2. a Cross-sectional areas of the intima of carotid arteries measured at 14 days after vessel injury. b Ratio of intima:medial area. Treatment groups defined as in fig. 1 . Values are means \pm SEM. ${ }^{*} \mathrm{p}<0.05,{ }^{* *} \mathrm{p}<0.01$, ${ }^{* * *} \mathrm{p}<0.001$ vs. C. ${ }^{\# \#} \mathrm{p}<0.01,{ }^{\# \#} \mathrm{p}<0.001$ vs. CG. ${ }^{\S} \mathrm{p}<0.001$ vs. CS.
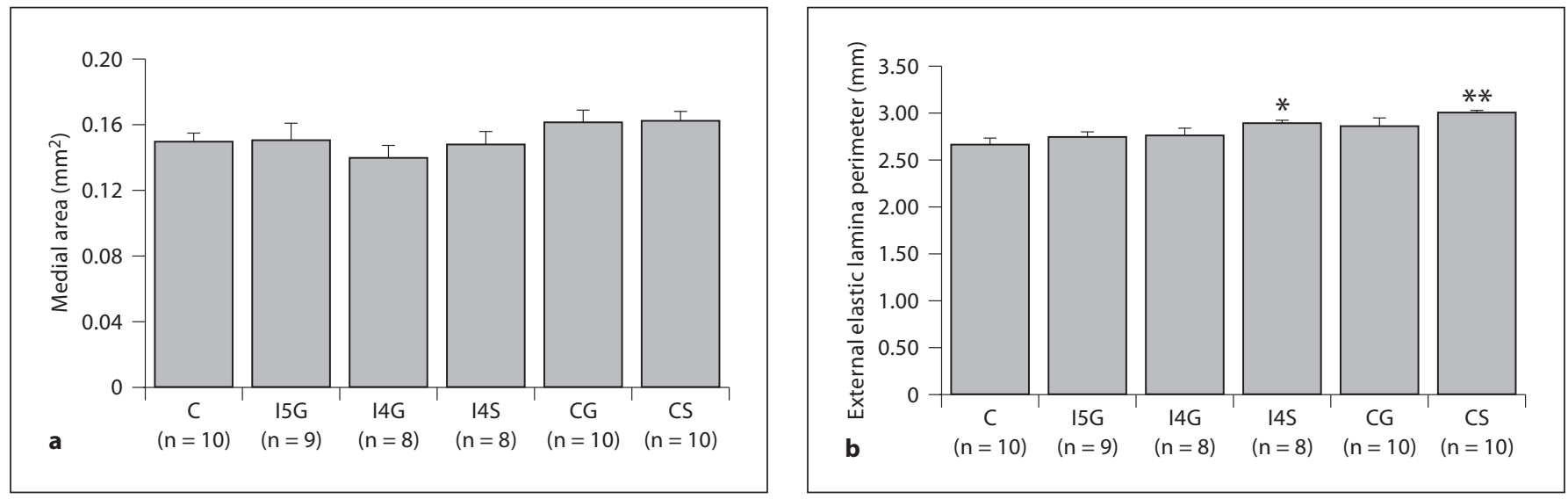

Fig. 3. Cross-sectional areas of the media (a) and external elastic lamina (b) of carotid arteries measured at 14 days after vessel injury. Treatment groups defined as in fig. 1 . Values are means \pm SEM. ${ }^{*} \mathrm{p}<0.05,{ }^{* *} \mathrm{p}<0.01$ vs. C.

els $(p<0.10$; table 4$)$. The fed FFA levels were not significantly changed in any group (table 4 ).

\section{Morphometric Measurements}

Figure 1 shows representative cross-sections of neointimal formation 14 days after balloon catheter injury of the carotid artery in all groups. Insulin treatment at a dose of $5 \mathrm{U} /$ day and $4 \mathrm{U} /$ day decreased neointimal thickening in rats receiving oral glucose compared to the control rats and those receiving oral glucose alone $(\mathrm{p}<0.001$; fig. $1,2 \mathrm{a})$. In contrast, rats receiving insulin treatment at $4 \mathrm{U} /$ day and oral sucrose had a similar neointimal area to control rats or those receiving oral glucose alone. Oral glucose alone did not have any effect on neointimal thickening versus control; however, oral sucrose increased neointimal thickening $(\mathrm{p}<0.05$; fig. $1,2 \mathrm{a})$. We also calculated the ratio of neointimal to medial thickness, which confirms our neointimal area results (fig. 2b). The calculated lumen area was significantly higher in both the 5U/day and 4-U/day insulin-treated groups receiving oral glucose, $0.24 \pm 0.02 \mathrm{~mm}^{2}$ and $0.22 \pm 0.02 \mathrm{~mm}^{2}$ respectively, compared to control, $0.15 \pm 0.02 \mathrm{~mm}^{2}(\mathrm{p}<0.05)$. The lumen area in the insulin (4 U/day)-treated rats receiving oral sucrose $\left(0.18 \pm 0.03 \mathrm{~mm}^{2}\right)$ and the CG group 


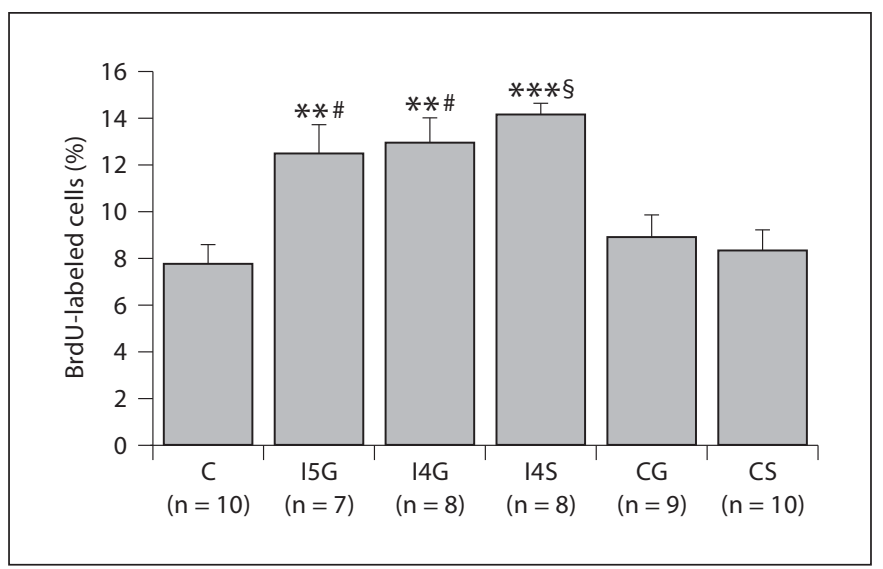

Fig. 4. Cell proliferation expressed as \% BrdU-labeled cells in the intima at 14 days after vessel injury. Treatment groups defined as in fig. 1 . Values are means \pm SEM. ${ }^{* *} p<0.01,{ }^{* *} p<0.001$ vs. C. ${ }^{\#} \mathrm{p}<0.05$ vs. CG. ${ }^{\S} \mathrm{p}<0.001$ vs. CS.

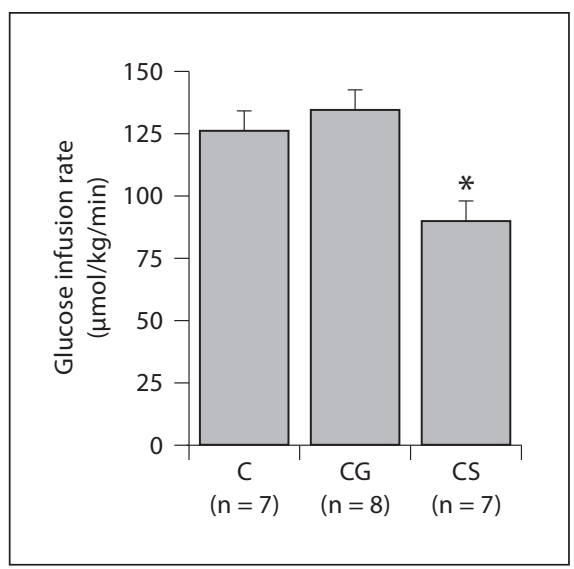

Fig. 5. Whole-body insulin sensitivity as indicated by the glucose infusion rate during the last $30 \mathrm{~min}$ of the 2-hour hyperinsulinemic-euglycemic clamp in C, CG- and CS-treated rats. Treatment groups defined as in fig. 1 . Values are expressed as mean \pm SEM. ${ }^{*} \mathrm{p}<0.05$ vs. C.

Table 5. Intimal SMC number and cell density per unit area measured at 14 days after arterial injury

\begin{tabular}{|c|c|c|c|c|c|c|}
\hline & $C(n=10)$ & $\mathrm{I} 5 \mathrm{G}(\mathrm{n}=7)$ & $\mathrm{I} 4 \mathrm{G}(\mathrm{n}=8)$ & $\mathrm{I} 4 \mathrm{~S}(\mathrm{n}=8)$ & CG $(n=9)$ & $\operatorname{CS}(\mathrm{n}=10)$ \\
\hline Intimal SMC, $\mathrm{n}$ & $1,276 \pm 93$ & $914 \pm 47^{*, \#}$ & $864 \pm 47^{*, \# \#}$ & $1,238 \pm 77$ & $1,308 \pm 162$ & $1,440 \pm 113$ \\
\hline Intimal SMC density, cells $/ \mathrm{mm}^{2}$ & $5,272 \pm 420$ & $7,250 \pm 846$ & $6,551 \pm 1,187$ & $5,798 \pm 274$ & $5,196 \pm 387$ & $4,930 \pm 146$ \\
\hline
\end{tabular}

Treatment groups defined as in table 2. Data are expressed as means \pm SEM. ${ }^{*} \mathrm{p}<0.05$ vs. C. ${ }^{\#} \mathrm{p}<0.05$, \#\# $\mathrm{p}<0.01$ vs. CG.

$\left(0.17 \pm 0.02 \mathrm{~mm}^{2}\right)$ were not significantly different than C. Lumen area had a slight tendency to decrease in the CS group $\left(0.12 \pm 0.01 \mathrm{~mm}^{2}\right)$ compared to $\mathrm{C}(\mathrm{p}<0.20)$. The medial area was similar among all groups. The external elastic lamina perimeter for the rats given oral sucrose had a very modest increase ( $\mathrm{p}<0.05$; fig. $3 \mathrm{a}, \mathrm{b})$.

Neointimal cell proliferation, evaluated as percent BrdU incorporation, was increased to a similar degree in the insulin-treated groups and was greater than $\mathrm{C}(\mathrm{p}<$ 0.01; fig. 4). Neointimal cell proliferation in the CG and CS groups was similar to $C$. The total number of cells was counted in the neointima and was significantly decreased in both insulin-treated groups receiving oral glucose $(\mathrm{p}<0.05$; table 5$)$. Neointimal cell density was calculated as the total number of cells divided by neointimal crosssectional area. Neointimal cell density tended to be greater in the insulin (5 U/day)-treated group compared to control $(\mathrm{p}<0.10$; table 5$)$.

\section{Insulin Sensitivity Measurements}

To test for the possibility that the sucrose-fed rats were insulin resistant and subsequently insulin was not able to exert its inhibitory effect on neointimal growth, we used a hyperinsulinemic-euglycemic clamp to measure insulin sensitivity after 16 days (equivalent to 2 days before and 14 days after carotid balloon injury) of treatment with oral glucose or oral sucrose. A $5 \mathrm{mU} / \mathrm{kg} /$ min insulin infusion rate was chosen to assess half-maximum glucose disposal (glucose infusion rate). The glucose infusion rate during the last $30 \mathrm{~min}$ of a 2 -hour hyperinsulinemic-euglycemic clamp is an indication of whole-body insulin sensitivity. Plasma insulin levels during the clamp were not significantly different (C $699 \pm 41$ pM, CG $702 \pm 27$ pM, CS $812 \pm 53$ pM). The glucose infusion rate was unchanged in rats receiving oral glucose treatment compared to those receiving tap water ( $p>0.05$; fig. 5), indicating that oral glucose did not affect insulin sensitivity. However, oral sucrose 
significantly decreased the glucose infusion rate $(\mathrm{p}<$ 0.05 ), suggesting that indeed oral sucrose induced insulin resistance in this model.

\section{Discussion}

In the present study, the in vivo effects of normoglycemic hyperinsulinemia and oral glucose or sucrose on neointima formation in the rat model of balloon catheter injury of the carotid artery were investigated. Neointimal, medial and lumen area, and neointimal cell proliferation, as well as metabolic parameters, were measured 14 days after arterial injury. In addition, insulin sensitivity was measured in a separate group of rats after the same length of treatment. Insulin treatment combined with oral glucose but not oral sucrose decreased neointimal area after arterial injury. Oral glucose alone had no such effect; however, oral sucrose had opposite effects to those of insulin on neointimal area, which may be attributed to a decrease in insulin sensitivity.

\section{Effect of Insulin and Oral Glucose}

Hyperinsulinemia was achieved in the insulin-treated groups as was desired. Normoglycemia was achieved in both the fasted and fed states in the insulin ( $5 \mathrm{U} /$ day)treated group by infusing glucose i.p. and by providing glucose in the drinking water. At the lower dose of insulin (4 U/day) oral glucose was sufficient to maintain normoglycemia. In contrast to our previous study, the plasma glucose levels of the insulin-treated groups were not lower than in controls. In the fasted state, FFA levels of the I5G and I4G group were lower than those of the control group. This was expected since insulin prevents lipolysis by inhibiting hormone-sensitive lipase [19].

In this study, insulin treatment in rats receiving oral glucose resulted in a decrease in neointimal thickness, an increase in the lumen area, and an increase in neointimal cell proliferation. Oral glucose, without insulin treatment, had no effect on neointimal, medial, or lumen area and neointimal cell proliferation when compared to control. Also, the increase in lumen area was not a result of outward remodeling since the external elastic lamina measured in these groups was the same.

In a previous study, we showed that insulin treatment in the rat model of balloon catheter injury of the carotid artery resulted in decreased neointimal growth at 14 days after injury [9]. However, in that study the insulin group had lower plasma glucose levels compared to control and it was unclear if the inhibitory effect on neointimal thick- ening seen was due to the insulin treatment or was a result of an insulin-induced decrease in plasma glucose. In this study, we achieved plasma glucose levels that were not only within the normal range, but also not significantly different from control. The decrease in neointimal thickness seen at 14 days despite the absence of changes in plasma glucose is consistent with a direct effect of insulin to decrease neointimal thickening. The extent of the percentage decrease was also comparable to that observed in the previous study [9], even though our absolute neointimal thickness is greater than in the previous study since a different experimenter was performing the surgery. Also notable and in accordance with our previous study [9] was the effect of insulin to increase neointimal cell proliferation despite a decrease in neointimal area after vessel injury, which suggests that insulin may have both growth-promoting and vascular protective effects. In our conditions though, the vascular protective effect of insulin to decrease neointimal area prevailed. An effect of insulin to inhibit SMC migration or induce apoptosis could explain why the total number of neointimal cells did not increase with insulin despite the increase in proliferation. We have shown that a lower dose of insulin (3 U/day) does inhibit cell migration without affecting apoptosis [11]. Furthermore, in the present study insulin (5 U/day) also tended to increase neointimal SMC density despite decreasing total neointimal SMC number, suggesting that insulin inhibits extracellular matrix accumulation, which we have observed previously [11]. A decrease in extracellular matrix accumulation in addition to insulin's inhibition of SMC migration would also result in a decrease in neointimal growth.

It was also important to assess the effect that oral glucose treatment alone may have on neointimal thickness. Therefore, an additional treatment group was included that received glucose in the drinking water. We found that oral glucose had no effect on neointimal thickness after arterial injury. This result indicates that insulin treatment, whether at a dose of 5 or $4 \mathrm{U} /$ day, reduces neointimal growth at 14 days after arterial injury independent of oral glucose administration.

In this study, insulin treatment at a high dose (5 U/day) reduced neointimal growth at 14 days after arterial injury in the presence of normoglycemia in rats fed a normal-fat control diet (12\% on a calorie basis), the same used in Kim et al. [9] and previously defined as 'low-fat' to differentiate it from the high-fat diet (matched for protein and micronutrients). In an earlier study, insulin treatment at a lower dose (3 U/day) had no significant effect on neointimal growth at 14 days after arterial injury in rats fed a stan- 
dard chow diet (Purina 5001), which had the same fat content ( $12 \%$ on a calorie basis) as the present diet. The insulin treatment at the lower dose did, however, reduce neointimal growth at 28 days after arterial injury in these chow-fed rats [11], suggesting a dose-dependent effect of insulin on decreasing neointimal growth rather than an effect of the diet. The lower dose of insulin [11] had no effect on proliferation, whereas the higher dose [9] increased it, in spite of its effect to decrease neointimal growth.

Our results are in keeping with some but not all the results in the literature. There are only a small number of studies examining the effect of insulin on neointimal thickness after balloon injury in non-diabetic models, and their results are conflicting. Indolfi et al. [20] have demonstrated that insulin treatment via islet transplantation increased neointimal growth, and similarly Pu et al. [21] have also shown that insulin infusion, using the same s.c. insulin-releasing pellet as in our studies, increases neointimal formation. On the other hand, Kubota et al. [22] showed that neointimal growth after cuff injury was greater in mice with a defect in insulin signaling (IRS-2 null mice). Recently, in agreement with our studies, glargine, an insulin analog, was shown to reduce neointimal formation in Zucker fatty rats [23], which exhibit hypertriglyceridemia, obesity, insulin resistance and hyperinsulinemia. These results are difficult to reconcile; however, a major difference between them is that in our studies [9,11] and in Murthy et al. [23] insulin treatment was initiated at approximately the time of surgery, whereas in Indolfi et al. [20] and Pu et al. [21] hyperinsulinemia was achieved several weeks ( $3-4$ weeks) before arterial injury and may thus have induced a state of insulin resistance. It is well known that in hyperinsulinemic/insulin resistant models neointimal growth is increased [24, 25]. Therefore it appears that under conditions of normal insulin sensitivity, insulin treatment decreases neointimal growth, whereas under conditions of insulin resistance (also insulin-induced) neointimal growth is increased; but it is impossible to attribute this to lack or excess of insulin action or to the generalized effects of insulin resistance/hyperinsulinemia (e.g. hyperlipidemia, minimal hyperglycemia). In our 2 models of insulin resistance (high-fat diet and sucrose feeding; see next paragraph) insulin given at the time of arterial injury was at least not detrimental. However, we have observed an effect of insulin to increase VSMC proliferation which remained intact under conditions of insulin resistance. Therefore, we cannot exclude that in other models of insulin resistance and under different experimental conditions, this effect may prevail and lead to neointimal hyperplasia.

\section{Effect of Insulin and Oral Sucrose}

We also examined the effect of oral sucrose alone and in combination with insulin on neointimal growth since insulin ( $\sim 3.9 \mathrm{U} /$ day) was shown to increase neointimal hyperplasia by Foster et al. [16] in rats where $10 \%$ sucrose water was used to maintain normoglycemia [16]. We found that in insulin-treated rats receiving oral sucrose, the inhibitory effect of insulin on neointimal growth was not observed while oral sucrose alone increased neointimal thickness after arterial injury. Interestingly, however, oral sucrose did not block the effect of insulin to increase neointimal cell proliferation, suggesting the development of selective insulin resistance.

Sucrose is a disaccharide of glucose and fructose. Both high-sucrose [26] and high-fructose [27] feeding are commonly used to induce insulin resistance in rats and studies have shown that fructose is the nutrient mediator of sucrose-induced insulin resistance [28]. Glucose feeding, however, did not affect insulin sensitivity [17]. We found that oral sucrose decreased insulin sensitivity compared to the tap water and oral glucose groups as assessed by a hyperinsulinemic-euglycemic clamp. In addition, the oral sucrose group in our study also tended to have increased fasting and fed triglyceride levels, which are associated with insulin resistance [29] and are observed after sucrose feeding as fructose bypasses the glucokinase checkpoint and also the phosphofructokinase checkpoint in the liver, immediately entering glycolysis and fatty acid synthesis [30, 31]. The oral sucrose group had elevated fasting plasma glucose levels, also suggesting that these rats were insulin resistant. Taken together, these data suggest that the increase in neointimal growth observed with oral sucrose feeding may be explained by hyperlipidemia, hyperglycemia and/or sucrose-induced insulin resistance. However, hyperlipidemia induced by a highfat diet increased both proliferation and neointimal growth [9], whereas oral sucrose only increased neointimal growth. Hyperglycemia may have played a role; however, the rats were not hyperglycemic in the fed state, which was the prevalent physiologic condition of our rats. Protein glycation induced by sucrose may be implicated and explain the increased external elastic perimeter, suggesting some vessel remodeling. Insulin resistance is also a likely possibility because insulin at lower plasma concentrations than those of the insulin-treated group of the present study (and thus more comparable to the basal insulin levels observed in the oral sucrose group) inhibits neointimal growth by decreasing cell migration and matrix accumulation without changing proliferation [11]. Therefore, it seems that in Foster et al. [16], the oral su- 
crose given to the insulin-treated rats reduced insulin sensitivity, thus blocking insulin's action to inhibit neointimal growth. Why in Foster's study insulin + oral sucrose actually increased neointimal growth, whereas in our study it only failed to decrease it compared to control, is not clear. We saw a slight decrease in fasting plasma glucose in our insulin + sucrose-treated group, whereas Foster did not report the fasting plasma glucose levels. However, as mentioned above, fasting was not the prevalent physiological condition of our rats. Furthermore, our present study and those we have performed previously [9] taken together suggest that slight decreases in plasma glucose do not affect neointimal growth. The dose of insulin is similar and the insulin levels are comparable in Foster's study and in ours; however, the rats in Foster's study are older than ours and perhaps more insulin resistant. It is possible that in our rats, but not in those of Foster's study, the effect on insulin was enough to coun- teract the effect of oral sucrose, whereas in Foster's study the effect of oral sucrose prevailed.

In conclusion, we demonstrate that insulin treatment reduces neointimal growth at 14 days after arterial injury due to an effect of insulin and not because of insulin-induced glucose lowering or oral glucose ingestion and that oral sucrose should not be used to maintain normoglycemia while giving insulin because it increases neointimal growth. Thus, these results further support a vascular protective effect of insulin in vivo.

\section{Acknowledgements}

This study was funded by a grant to A. Giacca from the Heart and Stroke Foundation of Canada (grant No. T-6476). D. Breen was supported by a Heart and Stroke Foundation of Ontario Graduate Scholarship, an Ontario Graduate Scholarship, and a Canadian Diabetes Association Doctoral Student Research Award.

\section{References}

1 Groop L, Orho-Melander M: The dysmetabolic syndrome. J Intern Med 2001;250:105120.

2 Grundy SM, Brewer HB Jr, Cleeman JI, Smith SC Jr, Lenfant C: Definition of metabolic syndrome: report of the National Heart, Lung, and Blood Institute/American Heart Association conference on scientific issues related to definition. Circulation 2004;109: 433-438.

-3 Alberti KG, Zimmet P, Shaw J: Metabolic syndrome: a new world-wide definition. A consensus statement from the International Diabetes Federation. Diabet Med 2006;23: 469-480.

4 Grundy SM: Metabolic syndrome: a multiplex cardiovascular risk factor. J Clin Endocrinol Metab 2007;92:399-404.

$\checkmark 5$ Ferrannini E: Metabolic syndrome: a solution in search of a problem. J Clin Endocrinol Metab 2007;92:396-398.

6 Piatti P, Di Mario C, Monti LD, Fragasso G, Sgura F, Caumo A, Setola E, Lucotti P, Galluccio E, Ronchi C, Origgi A, Zavaroni I, Margonato A, Colombo A: Association of insulin resistance, hyperleptinemia, and impaired nitric oxide release with in-stent restenosis in patients undergoing coronary stenting. Circulation 2003;108:2074-2081.

$\checkmark 7$ Ruige JB, Assendelft WJ, Dekker JM, Kostense PJ, Heine RJ, Bouter LM: Insulin and risk of cardiovascular disease: a metaanalysis. Circulation 1998;97:996-1001.
-8 Howard G, O'Leary DH, Zaccaro D, Haffner S, Rewers M, Hamman R, Selby JV, Saad MF, Savage P, Bergman R: Insulin sensitivity and atherosclerosis. The Insulin Resistance Atherosclerosis Study (IRAS) Investigators. Circulation 1996;93:1809-1817.

$\checkmark 9$ Kim T, Chan KK, Dhaliwall JK, Huynh N, Suen R, Uchino H, Naigamwalla D, Bendeck MP, Giacca A: Anti-atherogenic effect of insulin in vivo. J Vasc Res 2005;42:455-462.

10 Ridray S, Ktorza A, Picon L, Capron L: In vivo effect of insulin on the acute proliferative response of the rat aorta to injury. Arterioscler Thromb 1992;12:633-638.

- 11 Breen DM, Chan KK, Dhaliwall JK, Ward MR, Al KN, Lam L, De SM, Ghanim H, Dandona P, Stewart DJ, Bendeck MP, Giacca A: Insulin increases reendothelialization and inhibits cell migration and neointimal growth after arterial injury. Arterioscler Thromb Vasc Biol 2009;29:1060-1066.

$>12$ Nystrom T, Gonon AT, Sjoholm A, Pernow J: Glucagon-like peptide-1 relaxes rat conduit arteries via an endothelium-independent mechanism. Regul Pept 2005;125:173-177.

13 Gardiner SM, March JE, Kemp PA, Bennett T: Mesenteric vasoconstriction and hindquarters vasodilatation accompany the pressor actions of exendin- 4 in conscious rats. J Pharmacol Exp Ther 2006;316:852-859.

14 Nystrom T, Gutniak MK, Zhang Q, Zhang F, Holst JJ, Ahren B, Sjoholm A: Effects of glucagon-like peptide-1 on endothelial function in type 2 diabetes patients with stable coronary artery disease. Am J Physiol Endocrinol Metab 2004;287:E1209-E1215.
15 Kogire M, Inoue K, Sumi S, Doi R, Yun M, Kaji H, Tobe T: Effects of gastric inhibitory polypeptide and glucagon on portal venous and hepatic arterial flow in conscious dogs. Dig Dis Sci 1992;37:1666-1670.

16 Foster E, Zhang S, Kahn AM: Insulin stimulates arterial neointima formation in normal rats after balloon injury. Diabetes Obes Metab 2006;8:348-351.

17 Thorburn AW, Storlien LH, Jenkins AB, Khouri S, Kraegen EW: Fructose-induced in vivo insulin resistance and elevated plasma triglyceride levels in rats. Am J Clin Nutr 1989;49:1155-1163

18 Wang PY: The reliability of a compressed mixture of insulin and palmitic acid to sustain a reduction in hyperglycemia in rodents. ASAIO Trans 1987;33:319-322.

19 McTernan PG, Harte AL, Anderson LA, Green A, Smith SA, Holder JC, Barnett AH, Eggo MC, Kumar S: Insulin and rosiglitazone regulation of lipolysis and lipogenesis in human adipose tissue in vitro. Diabetes 2002;51:1493-1498.

-20 Indolfi C, Torella D, Cavuto L, Davalli AM, Coppola C, Esposito G, Carriero MV, Rapacciuolo A, Di Lorenzo E, Stabile E, Perrino C, Chieffo A, Pardo F, Chiariello M: Effects of balloon injury on neointimal hyperplasia in streptozotocin-induced diabetes and in hyperinsulinemic nondiabetic pancreatic islettransplanted rats. Circulation 2001; 103: 2980-2986. 
-21 Pu Q, Chang Y, Zhang C, Cai Y, Hassid A: Chronic insulin treatment suppresses PTP1B function, induces increased PDGF signaling, and amplifies neointima formation in the balloon-injured rat artery. Am J Physiol Heart Circ Physiol 2009;296:H132H139.

-22 Kubota T, Kubota N, Moroi M, Terauchi Y, Kobayashi T, Kamata K, Suzuki R, Tobe K, Namiki A, Aizawa S, Nagai R, Kadowaki T, Yamaguchi T: Lack of insulin receptor substrate-2 causes progressive neointima formation in response to vessel injury. Circulation 2003; 107:3073-3080.

23 Murthy SN, Sukhanov S, McGee J, Greco JA, Chandra S, Delafontaine P, Kadowitz PJ, McNamara DB, Fonseca VA: Insulin glargine reduces carotid intimal hyperplasia after balloon catheter injury in Zucker fatty rats possibly by reduction in oxidative stress. Mol Cell Biochem 2009, E-pub ahead of print.
24 Desouza CV, Gerety M, Hamel FG: Neointimal hyperplasia and vascular endothelial growth factor expression are increased in normoglycemic, insulin resistant, obese fatty rats. Atherosclerosis 2006;184:283-289.

25 Park SH, Marso SP, Zhou Z, Foroudi F, Topol EJ, Lincoff AM: Neointimal hyperplasia after arterial injury is increased in a rat model of non-insulin-dependent diabetes mellitus. Circulation 2001;104:815-819.

26 Brown AT, Smith TP, Cruz CP, Poirier LA, Simmons D, Williams DK, Wang Y, Eidt JF, Moursi MM: Intimal hyperplasia following carotid endarterectomy in an insulin-resistant rat model. Metabolism 2003;52:834839.

27 Lee MK, Miles PD, Khoursheed M, Gao KM, Moossa AR, Olefsky JM: Metabolic effects of troglitazone on fructose-induced insulin resistance in the rat. Diabetes 1994;43:14351439.
28 Thresher JS, Podolin DA, Wei Y, Mazzeo RS, Pagliassotti MJ: Comparison of the effects of sucrose and fructose on insulin action and glucose tolerance. Am J Physiol Regul Integr Comp Physiol 2000;279:R1334-R1340.

29 Koyama K, Chen G, Lee Y, Unger RH: Tissue triglycerides, insulin resistance, and insulin production: implications for hyperinsulinemia of obesity. Am J Physiol 1997;273: E708-E713.

30 Pagliassotti MJ, Prach PA, Koppenhafer TA, Pan DA: Changes in insulin action, triglycerides, and lipid composition during sucrose feeding in rats. Am J Physiol 1996;271: R1319-R1326.

-31 Kazumi T, Vranic M, Steiner G: Triglyceride kinetics: effects of dietary glucose, sucrose, or fructose alone or with hyperinsulinemia. Am J Physiol 1986;250:E325-E330. 